\title{
A IMAGEM NO DESENVOLVIMENTO DO PROJETO DE INICIAÇÃO CIENTÍFICA E TECNOLÓGICA JUNIOR EM ROBÓTICA EDUCATIVA
}

\author{
IMAGE IN THE DEVELOPMENT OF THE JUNIOR SCIENTIFIC AND \\ TECHNOLOGICAL INITIATION PROJECT ON EDUCATIONAL ROBOTICS
}

\author{
PORTO, Maria Beatriz Dias da Silva Maia ${ }^{1}$ \\ OLIVEIRA, Esequiel Rodrigues ${ }^{2}$
}

\begin{abstract}
RESUMO
A Robótica é a ciência que estuda a montagem e a programação de robôs. Os robôs são dispositivos programáveis que atuam de forma autônoma. As ações de construir e programar um robô exigem a combinação de conhecimentos de diversas áreas, ou seja, a robótica possui um caráter multidisciplinar. Algumas disciplinas presentes no estudo da robótica são a Física, a Eletrônica, o Design, a Matemática e a Informática. Por isso, as atividades de robótica são normalmente mais produtivas quando realizadas em grupo e por pessoas de diferentes áreas, o que as torna potencialmente indicadas ao ensino interdisciplinar. Neste trabalho, enfatizamos a iniciação à robótica, através da utilização de imagens. Mais que colorida e interessante aos olhos, na programação de robôs descrita neste estudo, a "linguagem de programação" - construção de algoritmo - é mediada por imagem, aqui tratada no campo da modalidade linguística. A interface multimodal, que reúne no texto a palavra e a imagem, é predominantemente gráfica, o que reduz a necessidade de digitação de scripts, diminuindo o tempo da programação. Este trabalho relata uma experiência de ensino de Física, desenvolvida na forma de projeto de Iniciação Científica e Tecnológica Junior, e reflete sobre questões relacionadas a imagem e conhecimento, apontando para outras possibilidades no ensino e na pesquisa na Educação Básica.
\end{abstract}

PalaVRas-chaVe: Robótica; Ensino de Física; Imagem e conhecimento.

\begin{abstract}
Robotics is the science that studies the assembly and programming of robots. Robots are programmable devices that act autonomously. The actions of building and programming a robot require the combination of knowledge from different areas, that is, robotics has a multidisciplinary character. Some disciplines present in the study of Robotics are Physics, Electronics, Design, Mathematics and Information Technology. Therefore, robotic activities are usually more productive when performed in groups and by people from different areas,

\footnotetext{
${ }^{1}$ Professora Adjunta da Universidade do Estado do Rio de Janeiro - Instituto de Aplicação Fernando Rodrigues da Silveira - Departamento de Ciências da Natureza; Professora do Programa de PósGraduação em Ensino de Educação Básica (PPGEB/UERJ). E-mail: beatrizrj@mail.com

${ }^{2}$ Professor Adjunto da Universidade do Estado do Rio de Janeiro - Instituto de Aplicação Fernando Rodrigues da Silveira - Departamento de Matemática e Desenho; Professor do Programa de PósGraduação em Ensino de Educação Básica (PPGEB/UERJ). E-mail: esequiel.rodri@gmail.com
} 
which makes them potentially suitable for interdisciplinary teaching. In this work, we emphasize Robotic initiation through the use of images. More than colorful and interesting to the eye, in the programming of robots described in this study, the "programming language" algorithm construction - is mediated by image, here dealt within the field of linguistic modality. The multimodal interface, which joins word and image in the text, is predominantly graphic, reducing the need to enter scripts and reducing programming time. The work reports an experience of teaching Physics, developed in the form of a Junior Scientific and Technological Initiation project, and reflects on questions related to image and knowledge, pointing to other possibilities in teaching and research on Basic Education.

KeYwORDS: Robotics, Physics teaching, Image and knowledge.

\section{A Robótica e a Iniciação Científica}

A Robótica é a ciência que estuda a montagem e a programação de robôs. Os robôs são dispositivos autônomos, programáveis, controlados por programas de computador (SECCHI, 2008). As ações de construir e programar um robô exigem a combinação de conhecimentos de diversas áreas, ou seja, a Robótica possui um caráter multidisciplinar. Algumas disciplinas presentes no estudo da robótica são a Física, a Eletrônica, o Design, a Matemática e a Informática. Por isso as atividades de Robótica são normalmente mais produtivas quando realizadas em grupo e por pessoas de diferentes áreas, o que as torna potencialmente indicadas ao ensino interdisciplinar, desenvolvendo competências como: solução de problemas, exposição de ideias e elaboração de conceitos interdisciplinares, estimulando a criatividade. Devido a essas características, diversos eventos têm sido organizados para a Educação Básica, como forma de estimular e difundir as aplicabilidades dessa área de conhecimento. Dentre estes eventos é possível citar: a última fase do "Torneio de Robótica First Lego League ${ }_{-13}$, promovido pelo Serviço Social da Indústria (SESI), anual, e cuja última fase ocorreu em março de 2016, em Brasília (DF); a Mostra Nacional de Robótica (MNR) ${ }^{4}$, que em 2016 aconteceu no mês de outubro, em Olinda/PE. Tais eventos visam a estimular o surgimento de ações inovadoras com diferentes finalidades e viabilizam pesquisas sobre novas formas de ensino, tanto na Educação Básica quanto no Ensino Superior. Essas ações podem ser na forma de atividades de Extensão ou de projetos de Iniciação Científica.

No caso específico deste artigo será apresentado o projeto de Iniciação Científica e Tecnológica Junior, desenvolvido com estudantes do Ensino Médio do Instituto de Aplicação Fernando Rodrigues da Silveira, o CAp-UERJ. O projeto de Iniciação Científica e Tecnológica Júnior em Robótica Educativa no CAp-UERJ se constitui em um campo de pesquisa para o ensino de Física e de investigações interdisciplinares.

\footnotetext{
${ }^{3}$ Disponível em: http://www.brasil.gov.br/ciencia-e-tecnologia/2016/03/maior-torneio-de-robotica-dopais-comeca-neste-sabado-em-brasilia. Acesso em: 11 de novembro de 2016.

${ }^{4}$ Disponível em: http://www.mnr.org.br/. Acesso em: 11 de novembro de 2016.
} 
Fig. 1 - Robô Lego Mindstorms NXT 2.0

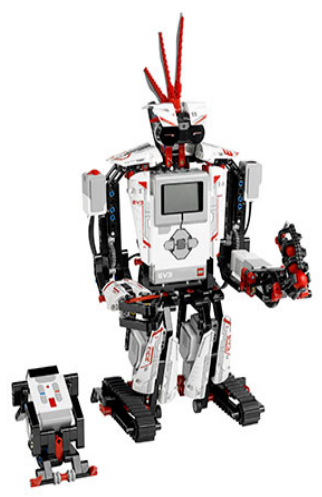

Fonte: http://www.lego.com/en-us/mindstorms/?domainredir=mindstorms.lego.com

As montagens das diversas configurações de Robô neste projeto foram realizadas com o kit do robô LEGO MINDSTORMS NXT 2.0 (fig.1). O kit é composto por um grande arsenal de peças, o que possibilita a montagem dos mais diversos dispositivos, e um software que permite programá-los através de um material bastante simples, que utiliza imagens que orientam a associação de blocos para a construção dos objetos, típicas de manuais.

Fig. 2 - Manual do Robô LEGO MINDSTORMS NXT 2.0

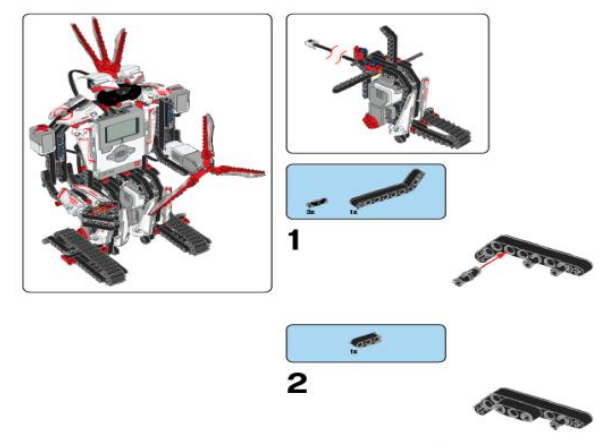

Fonte: http://www.lego.com/en-us/mindstorms/?domainredir=mindstorms.lego.com

Em geral, os manuais de montagem de produtos são baseados em muitas imagens, algumas palavras e números (fig. 2). Para um consumidor comum esses documentos perdem a importância após o encaixe da última peça. Porém, para a pesquisa em ensino, este tipo de texto tem grande importância, tanto para avaliar e desenvolver habilidade de leitura, quanto para investigar a aprendizagem de conceitos científicos envolvidos, nesse caso, o funcionamento de um robô. E da 
aprendizagem resultam novas experiências e consequentes possibilidades de inovações tecnológicas.

Desse modo, as imagens, as palavras e os números aqui são objetos de estudo, enquanto texto híbrido no qual predomina a imagem. Neste artigo fazemos uma reflexão sobre a importância da imagem para o desenvolvimento e implantação da Robótica Educativa na Educação Básica.

Realizado no Instituto de Aplicação Fernando Rodrigues da Silveira, o projeto foi elaborado com o propósito de estimular o interesse dos estudantes da Educação Básica pelas áreas da Engenharia e reduzir a evasão que ocorre nesse curso durante os seus ciclos básicos. O estudo contou com o financiamento do $\mathrm{CNPq}^{5}$ e nele estavam envolvidos oito participantes, sendo dois professores da Engenharia, uma professora de Física que atua na Educação Básica, um estudante da Engenharia e quatro estudantes do Ensino Médio do CAp-UERJ.

Os Coordenadores do projeto buscaram, dentre outros incentivos, apresentar aos estudantes da Educação Básica participantes, os conceitos da área de Física estudados a partir do nono ano do Ensino Fundamental, através de aplicações em Robótica. No desenvolvimento do trabalho a utilização de imagens revelou-se fundamental e indispensável, tanto para a montagem do robô quanto para a sua programação, o que motivou este artigo. Esta reflexão teve origem na cooperação entre o grupo de pesquisa LINGUAGEM E EDUCAÇÃO: ENSINO E CIÊNCIA, na linha Linguagens, Transdisciplinaridade, Tecnologia e Ensino, e o grupo ALFABETIZAÇÃO CIENTÍFICA E O ENSINO DE FÍSICA, QUIMICA E BIOLOGIA NA ESCOLA BÁSICA, visando à compreensão das linguagens das Ciências Naturais e Sociais, decorrente da organização da experiência através da tecnologia, pelo que propicia como Ambiente de Aprendizagem, particularizando a análise do potencial da imagem na elaboração de conceitos científicos e suas aplicações no desenvolvimento tecnológico.

Assim, o trabalho relata uma experiência de ensino de Física, reflete sobre as questões relativas à imagem e o conhecimento, e aponta para outras possibilidades no ensino e na pesquisa na Educação Básica.

\section{LINGUAGEM VISUAL — UMA PERSPECTIVA DISCIPLINAR}

A importância da imagem no desenvolvimento do conhecimento científico tem sido objeto de estudo em diferentes pesquisas no campo da história das Ciências e das Artes. Erwin Panofsky (1892-1968) sustenta que ao criarem o espaço-sistema ${ }^{6}$ para representação na pintura do século $X V$, os artistas florentinos criam um novo modo de ver, de compreender o espaço e a natureza, executando obras que

\footnotetext{
${ }^{5}$ Chamada CNPq/VALE S.A. FORMA-ENGENHARIA.

${ }^{6}$ Oposto ao espaço-agregado, tipicamente medieval, cuja noção de profundidade é obtida através da justaposição dos elementos, sem considerar as relações de dimensões e distâncias entre eles.
} 
retratavam paisagens naturais e urbanas. Tal proposição é essencial para as descobertas da Ciência Moderna (THUILLIER, 1994).

No conceito de espaço-sistema o objeto representado tem lugar definido e dimensões proporcionais às suas dimensões reais e à distância em que se encontra de um observador que vê todo o conjunto, a partir de uma posição conhecida como de ponto de vista (Fig. 3).

Fig. 3 - Sistema de representação em perspectiva

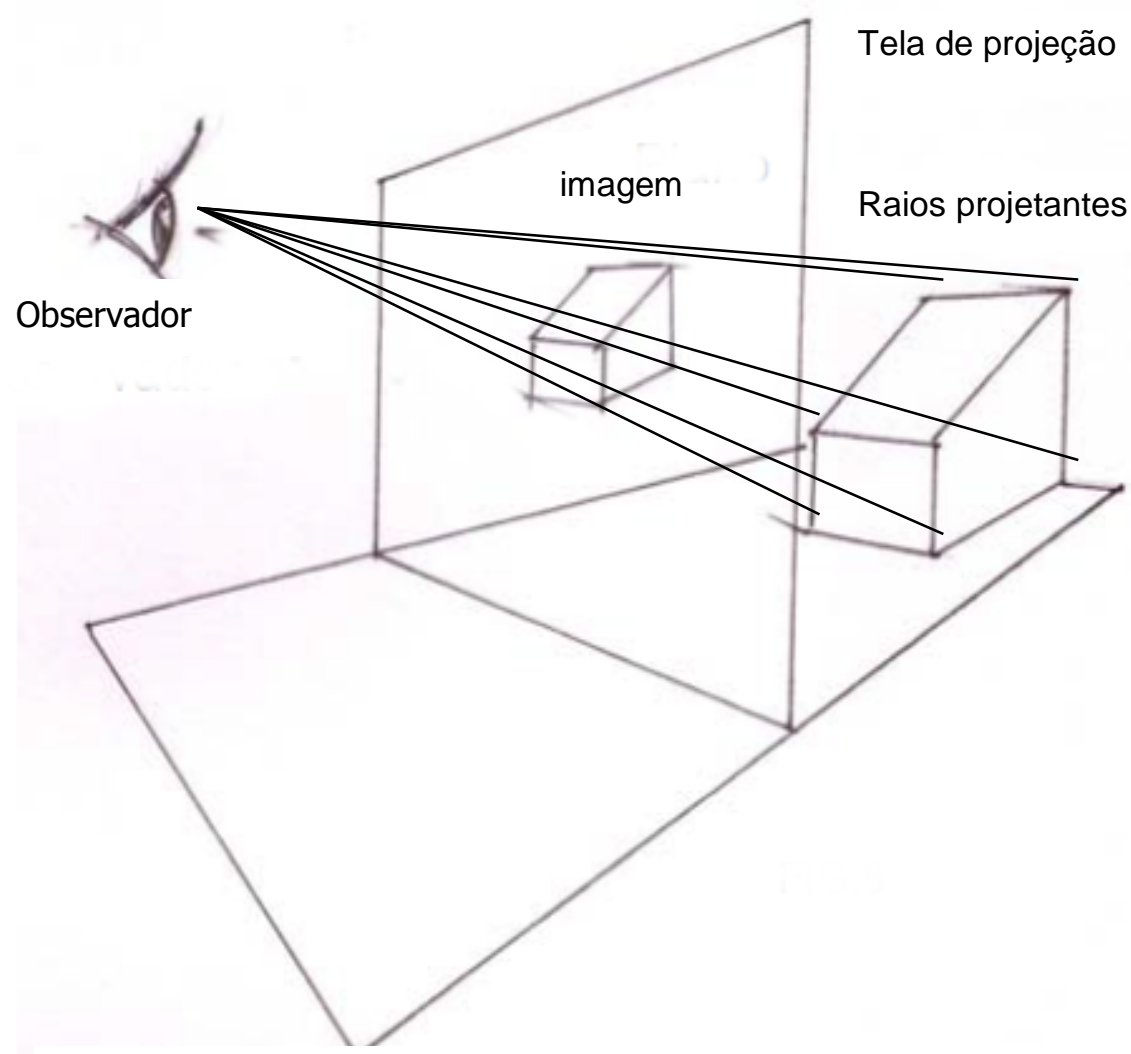

Fonte: material da pesquisa

A necessidade de determinar tais proporções estimulou o desenvolvimento de cálculos matemáticos, resultando no que foi chamado geometrização do espaço. 0 espaço (lugar) é concebido antes dos elementos que nele são precisamente posicionados. De determinado ponto de vista, baseado nos conceitos da Óptica Geométrica, a percepção visual humana intui a convergência das linhas paralelas da cena a um ponto, denominado ponto de fuga. Dito de outra forma, o ponto de vista pode ser compreendido como o olho de quem vê a cena (ou objeto), e o ponto de fuga é imagem do ponto de vista no desenho (figs. 4a e 4b). Em Matemática, o ponto de vista é denominado centro projetivo (de onde partem retas - raios projetantes - que passam pelos pontos da superfície de um objeto) e o ponto de fuga, a projeção deste no plano onde se forma a imagem. Em Física, os raios 
e-Mosaicos - Revista Multidisciplinar de Ensino, Pesquisa, Extensão e Cultura do Instituto de Aplicação Fernando Rodrigues da Silveira (CAp-UERJ) V. 6 - N. 12 - AGOSTO 2017 - ISSN: 2316-9303

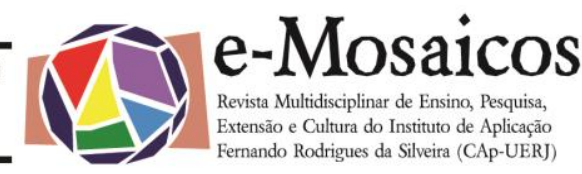

DOI 10.12957/e-mosaicos.2017.28610

projetantes podem ser compreendidos como os raios luminosos refletidos pelo objeto. É importante esclarecer que um ponto de vista pode gerar mais de um ponto de fuga na mesma imagem.

Figs. 4a, mais inferior, e $\mathbf{4 b}$, a seguir. A imagem $4 a$ apresenta dois pontos de fuga, indicados pelas linhas tracejadas, enquanto na imagem $4 \mathrm{~b}$, as linhas paralelas no objeto são representadas paralelas. Esta imagem resulta da concepção de um observador situado a uma distância infinita do objeto. Trata-se de uma idealização adequada às imagens técnicas.

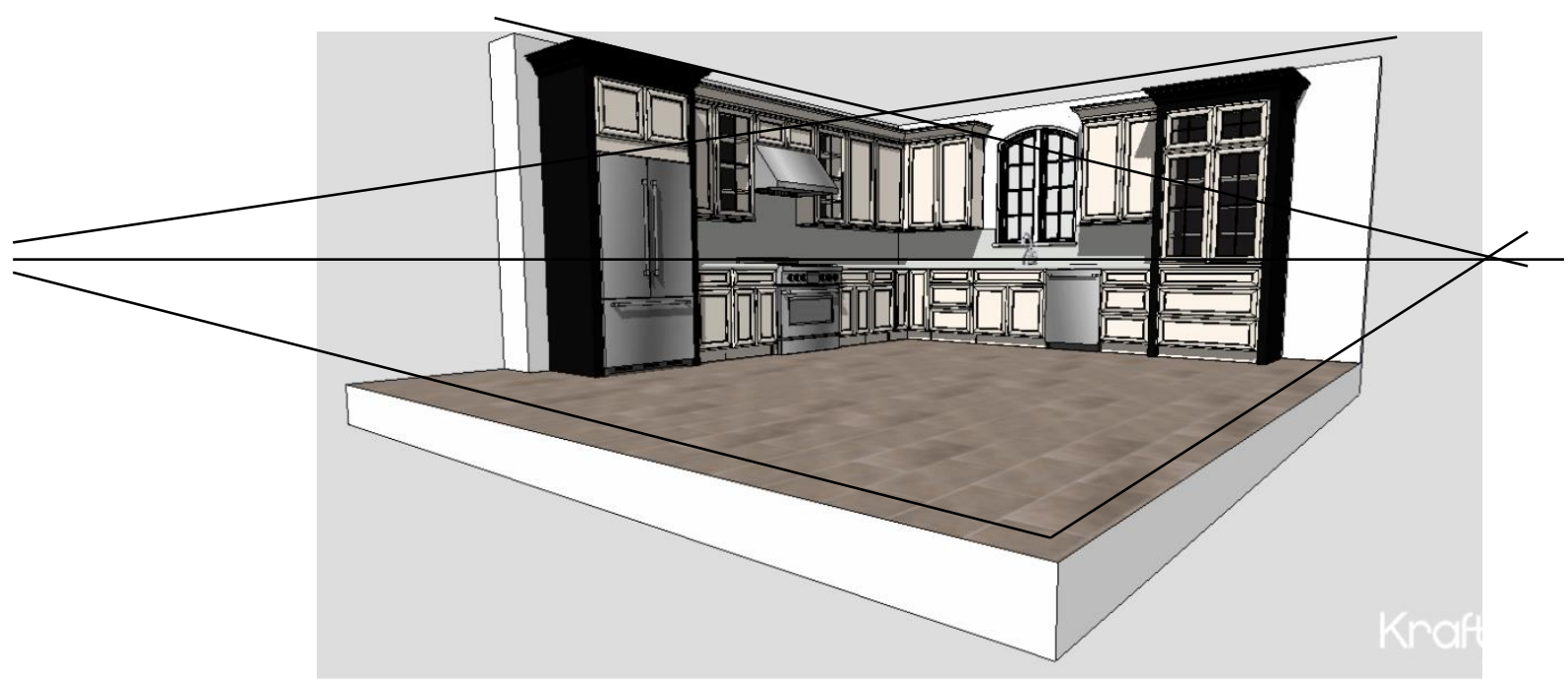

Fonte : https://3dwarehouse.sketchup.com/?hl=pt-BR . Acesso em 14 de novembro de 2016.

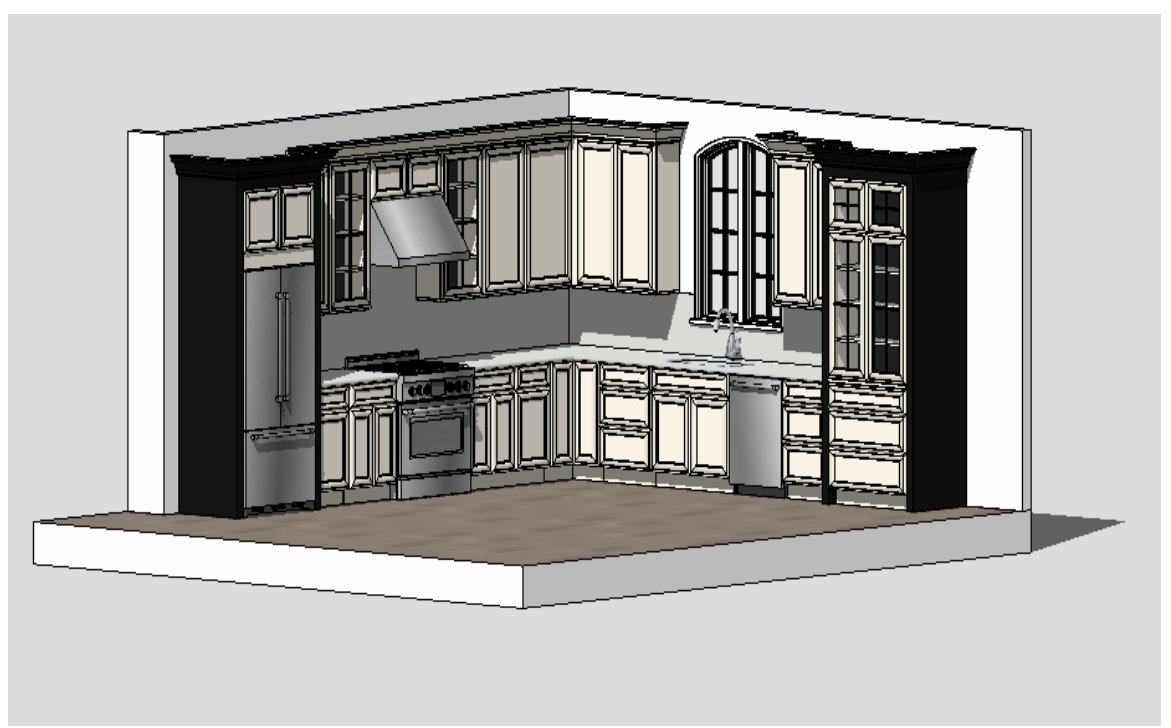

Fonte : https://3dwarehouse.sketchup.com/?hl=pt-BR . Acesso em 14 de novembro de 2016. 
Esta simples demonstração, intuitiva para os artistas florentinos, precedeu as noções modernas de tempo e espaço desenvolvidas por Galileu (1564-1642) e Newton (1643-1727). Mais de cem anos antes Leon Batisti Alberti (1404-1472) escreveu o tratado "Sobre Pintura", cuja exposição sobre perspectiva "é concebida expressamente dentro de um espírito matemático e se baseia em conhecimentos sólidos de geometria e óptica" (TRUILLIER, 1994, p. 65-66). Para Truillier a descoberta da perspectiva inspira investigações multidisciplinares do espaço, uma vez que este, a partir de então, é concebido infinito. A Engenharia e a Arquitetura gradativamente desvinculam a atividade projetiva da executiva, lançando assim, as bases para a Revolução Industrial. A partir de então as ações de projetar e executar passaram a ser realizadas por grupos diferentes, permitindo, deste modo, o aumento da produtividade (EDGERTON, 1975). Em alguns aspectos, e na devida proporção, essa premissa também é válida para refletir sobre a revolução da comunicação e informação da atualidade.

Se hoje os projetos e modelos são desenvolvidos por computação gráfica, há que se considerar a base matemática dessas ferramentas e os conhecimentos multidisciplinares envolvidos na produção e testagem dos modelos. A Matemática, a Física, a Engenharia, o Design, a Comunicação, a Inclusão Social, a Economia, entre outras, são áreas de conhecimento que contribuem para desenvolvimento de protótipos de veículos, propostas urbanísticas, aparelhos de musculação, equipamentos hospitalares, etc. E o que dizer da imagem nesse contexto?

Não menos importante, mas diferente da contribuição intuitiva de artistas na criação da perspectiva linear, hoje ela é meio de visualização do produto. Viabiliza o desenho (modelagem), a testagem (por simulação), o cálculo do custo, a reprodução por impressão 3D e a elaboração do manual de utilização. Tudo isso disponível a um consumidor médio ${ }^{7}$, seja ele um pesquisador; um arquiteto ou um educador, dedicado à confecção de material didático. Nesse caso, qualquer que seja a motivação, a imagem é o meio de relacionar espaço, proporção, forma, movimento e cor, unindo linhas, figuras planas e superfícies tridimensionais, na criação de algo. De transformar o pensamento em realidade. A esse respeito Machado (2001, p. 23), afirma:

A ciência e a civilização dos séculos XIX e XX são impensáveis sem o papel estrutural e constitutivo nelas desempenhado pela imagem (da iconografia científica, da fotografia, do cinema, da televisão e dos novos meios digitais). Essa parte da humanidade não aprendeu apenas a conviver com as imagens, mas também a pensar com as imagens e a construir com elas uma civilização complexa e instigante. $\mathrm{Na}$ verdade, hoje estamos realmente em condições de avaliar a

\footnotetext{
${ }^{7}$ As impressoras 3D estão à venda em grandes redes de varejo de informática, a preços médios de $\mathrm{R} \$$ $5.500,00:$ http://busca.livrariasaraiva.com.br/search\#w=impressora\%203d\&PAC_ID=\&af=cat1\%3a informatica.
} 
extensão e a profundidade do acervo iconográfico construído e acumulado pela humanidade (...), pois somente agora nos é possível compreender a natureza mais profunda do discurso iconográfico, isso que poderíamos chamar de linguagem das imagens, capaz de expressar realidades diferentes, historicamente abafadas (...)".

A linguagem da imagem citada por Machado ou a língua da imagem (BARTHES, 1990) apresenta, além dos aspectos morfológicos e sintáticos já mencionados, o semântico. A fotografia de uma esteira ergométrica pode remeter a noções diversas, como: prazer, saúde, boa forma física e rotina. Os sentidos atribuídos decorrerão da experiência do indivíduo que a vê e do contexto em que ela for apresentada. Assim, a imagem adquire o estatuto de produto da linguagem, sua dimensão ideológica (BAKHTIN, 2004), considerando a linguagem como sistema de signos usados para a comunicação e derivar a linguagem visual, musical, a matemática, etc. Por ela agimos física ou mentalmente diante de um sistema estabelecido e da sua perspectiva de evolução constante, que se concretiza nos atos de comunicação cotidianos.

Se privarmos a consciência de seu conteúdo semiótico e ideológico, não sobra nada. A imagem, a palavra, o gesto significante etc., constituem o seu único abrigo. Fora desse, material há apenas um ato fisiológico, não esclarecido pela consciência, desprovido do sentido que os signos the conferem (BAKHTIN, 2004, p. 36).

Cada sistema possui especificidades: uns são mais flexíveis, admitindo códigos gerais; outros menos, mais adequados à multiplicidade de códigos restritos a determinados contextos. Por ser arbitrário, o modo verbal é o mais adaptável das linguagens, enquanto que a imagem, devido a sua dimensão analógica da realidade visual, é mais suscetível a produzir códigos nos domínios discursivos em que se concretiza, como no caso da esteira. Assim, tem prevalecido entre os teóricos da semiótica a tese de que a Linguagem Visual deve ser estudada no âmbito do texto (ECO, 1976; CALABRESE, 1980, apud, SANTAELLA e NOTH, 2008).

O texto, no sentido amplo de conjunto coerente de signos, representa uma realidade imediata do pensamento e da emoção (BAKHTIN, 1997), que se distingue do sistema de signos que se relacionam de forma organizada, o código. Serve-se dessa base técnica apenas para expressar-se em determinado contexto. Significa que em contextos distintos textos se produzem a partir de um mesmo conjunto de signos, diferentes sentidos são construídos. O texto se completa quando é compreendido. Assim, o estudo do potencial da imagem na produção de conhecimento implica no estudo dos gêneros e dos tipos textuais e suas possibilidades discursivas; na articulação entre aspectos abstratos (da forma) e concretos (do conteúdo) no processo de significação. Os gêneros textuais são: "(...) textos materializados que encontramos em nossa vida diária e que apresentam 
características sócio-comunicativas definidas por conteúdos, propriedades funcionais, estilo e composição característica." (MARCHUSCHI, 2002, pag. 22-23).

O conceito admite um amplo e diversificado conjunto de exemplos: carta, telefonema, horóscopo, edital, conversa, entrevista e bula, na modalidade textual verbal; pintura, desenho, jogo eletrônico, escultura, caricatura, na modalidade textual visual. O termo modalidade textual refere-se à produção de significado a partir de um texto constituído por apenas um sistema de signos (KRESS e LEEUWEN, 2001). Desse modo, quando a significação se dá a partir de dois ou mais sistemas de signos o texto é denominado multimodal. Nesse sentido, os manuais podem ser classificados como textos multimodais. Neles articulam-se palavras, números e imagens, nos impressos; os eletrônicos associam, ainda, sons e animações.

Enquanto os gêneros são inúmeros, o estudo tipológico apresenta apenas cinco categorias: narração, argumentação, exposição, descrição e injunção. Os tipos textuais se caracterizam pelas relações lógicas e sintáticas, entre outras. O manual apresenta a imagem em perspectiva cilíndrica (fig. 4b), já os folders de divulgação de produtos para venda utilizam a perspectiva cônica (fig. 4a). Isto porque 0 primeiro pretende comunicar dimensões e proporções de forma clara, já o segundo focaliza aspectos estéticos e funcionais, sendo mais adequado à divulgação do produto. Ambos, porém, são tipos narrativos, expõem a ideia do objeto e evocam memórias, inspirando fatos novos (MANGUEL, 2001).

Além da forma, a cor integra o processo de significação do texto visual de forma determinante. Fatores sensoriais e sociais interferem na escolha das cores. Estes têm sido objeto de estudo em diferentes áreas de conhecimento, desde a saúde até a comunicação, os estudos têm inúmeras motivações, dentre as quais a publicitária, que dela se serve para influenciar o consumidor.

As cores constituem estímulos psicológicos para a sensibilidade humana, influindo no indivíduo para gostar ou não gostar de algo, para se negar ou afirmar, para se abster ou agir. Muitas preferências sobre as cores se baseiam em associações ou experiências tidas no passado e, portanto, torna-se difícil mudar as preferências sobre as mesmas (FARINA, 1986, p. 112. Grifos nossos).

A publicidade tem metas a atingir, por isso mune-se de conhecimentos e recursos que assegurem maior eficácia na comunicação em seus textos. No que tange à comunicabilidade o ensino escolar tem a mesma pretensão, não para apreender o pensamento, ao contrário, para contribuir com a expansão das possibilidades de criação. Então, o domínio de códigos linguísticos é necessário nos atos de comunicação, como ponto de partida, embora tenham limitações operatórias e criadoras na aquisição de conhecimentos. Daí a plasticidade do texto na produção de sentidos no ato da leitura. 
A imagem em perspectiva é codificada, segundo as normas da representação e precisa ser assim, mas o colorido da forma em perspectiva, pode ser ou não. Depende do gênero textual e sua finalidade, e da sua natureza modal ou multimodal. Neste projeto, em alguns textos a cor constitui a base do código. É o que se pode constatar nas etapas do projeto.

\section{ROBÓTICA - CAMINHOS INVESTIGATIVOS}

O desenvolvimento se deu em três etapas já concluídas. São elas: a iniciação do estudante na atividade científica e nos estudos da robótica; a programação para realizar ações; os resultados decorrentes da aprendizagem da Física e da Robótica.

\section{INICIAÇÃo do ESTUdANTE NA ATIVIDADE CiENTÍFICA E NOS Estudos DA RoBÓTICA}

A primeira etapa do Projeto consistiu de um minicurso, ministrado por estudante do Curso de Engenharia, também bolsista do CNPQ, com o objetivo de apresentar o kit de robótica para os estudantes do Ensino Médio e de alguns exemplos de programação para o robô.

A partir de uma sequência de imagens organizadas em apresentação Powerpoint, os estudantes montavam e testavam os exemplos apresentados.

Dentre as peças que compõem o kit de robótica, o LEGO MINDSTORMS NXT 2.0, as mais utilizadas foram, principalmente: 1 bloco lógico programável, que identificamos como o "cérebro" do robô, possuidor de sete entradas; 3 servomotores elétricos, que se distinguem dos motores elétricos pelo fato de poderem ser programados; 2 sensores de toque, que fornecem ao robô o sentido de tato; 1 sensor de luminosidade, que pode ser operado no modo luz ou no modo cor, utilizando ondas eletromagnéticas, fornecendo o sentido de visão ao robô; 1 sensor de ultrassom, que também fornece o sentido de visão ao robô, utilizando ondas sonoras; diversas peças, como vigas, engrenagens, correias, buchas, rodas e pneus.

A montagem do robô foi a primeira ação de todas as atividades realizadas, ou seja, o Design da sua estrutura. Já neste momento, a utilização de imagens revelouse fundamental. Montar a estrutura de um robô não é simples. Portanto, todas as etapas da montagem foram transformadas em imagens e projetadas para que os alunos da Educação Básica pudessem acompanhar o processo de montagem e programação. Ainda durante a realização do minicurso, foram montadas e programadas as seguintes empreitadas: o robô que recua ao detectar uma linha vermelha e o robô separador de cores.

\section{O robô que recua ao detectar uma linha vermelha}

O objetivo dessa montagem, seguida de programação, é obter um robô que ao detectar uma linha vermelha retorne, seguindo o mesmo percurso por onde veio. 
Para tanto, foram fornecidas ao grupo um conjunto de imagens para orientação. 0 objetivo era conseguir a estrutura da figura 5:

Fig. 5 - Robô Detector de Cores

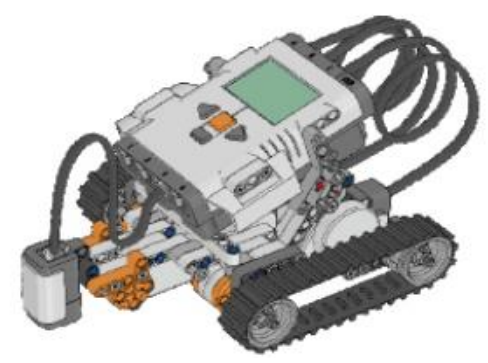

Fonte: http://www.lego.com/en-us/mindstorms/?domainredir=mindstorms.lego.com

Os estudantes realizaram a montagem do dispositivo utilizando uma sequência de vinte e seis imagens. A figura 6 mostra algumas das imagens apresentadas aos alunos:

Fig. 6 - Imagens $n^{0 s} 1,8,16,25$ da sequência de 26 imagens
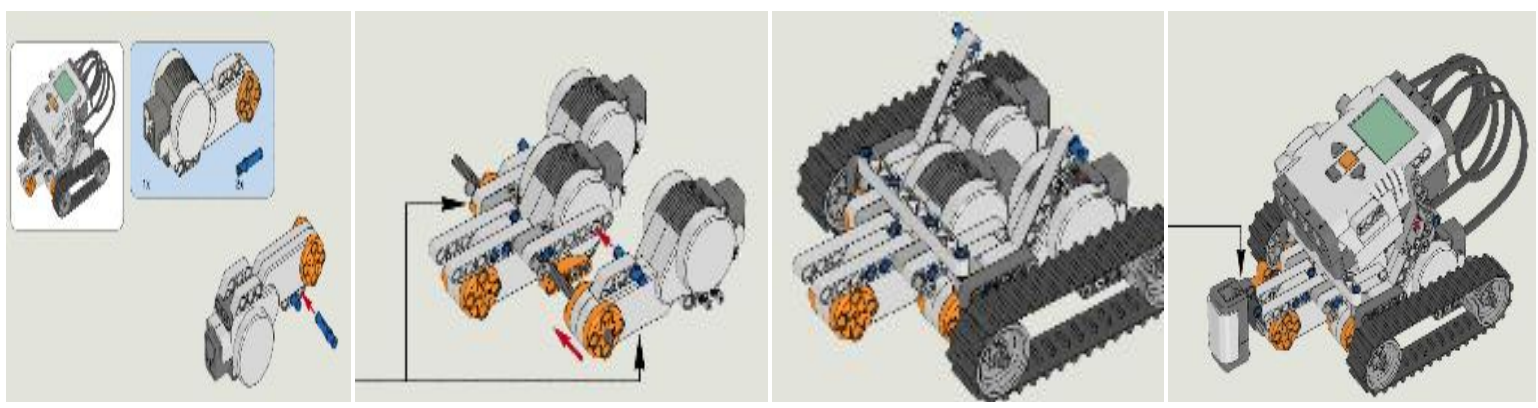

Fonte: http://www.lego.com/en-us/mindstorms/?domainredir=mindstorms.lego.com

O sensor de cor indicado na última imagem tem um papel fundamental. Dele parte luz com três comprimentos de onda diferentes, quais sejam: verde, vermelha e azul. O reconhecimento da linha vermelha é realizado pelo sensor através da reflexão de ondas eletromagnéticas. $O$ sensor emite luz nas cores verde, vermelha e azul e, quando é detectada a linha vermelha, as cores azul e verde são absorvidas enquanto a vermelha a ele retorna, por reflexão. Detectando a linha, o robô retorna. 


\section{O Robô Separador de Bolinhas por cor}

A segunda empreitada realizada consistiu na montagem e programação do robô separador de bolinhas, de acordo com a cor. No que diz respeito à montagem, foram fornecidas aos estudantes participantes quatro sequências de imagens, totalizando cento e quarenta e oito. Cada sequência revelava-se bastante trabalhosa. O objetivo era conseguir a estrutura montada na figura 7.

Fig. 7: Robô separador de bolinhas

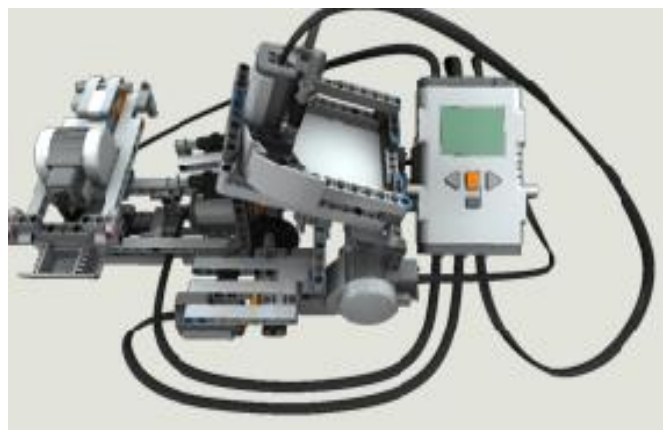

Fonte: http://www.lego.com/en-us/mindstorms/?domainredir=mindstorms.lego.com

A primeira parte consistiu na montagem do "dispenser". Eram, ao todo, cento e duas imagens. São mostradas a seguir oito destas imagens:

Fig. 8: Imagens extraídas da sequência da montagem do dispenser do separador de bolinhas
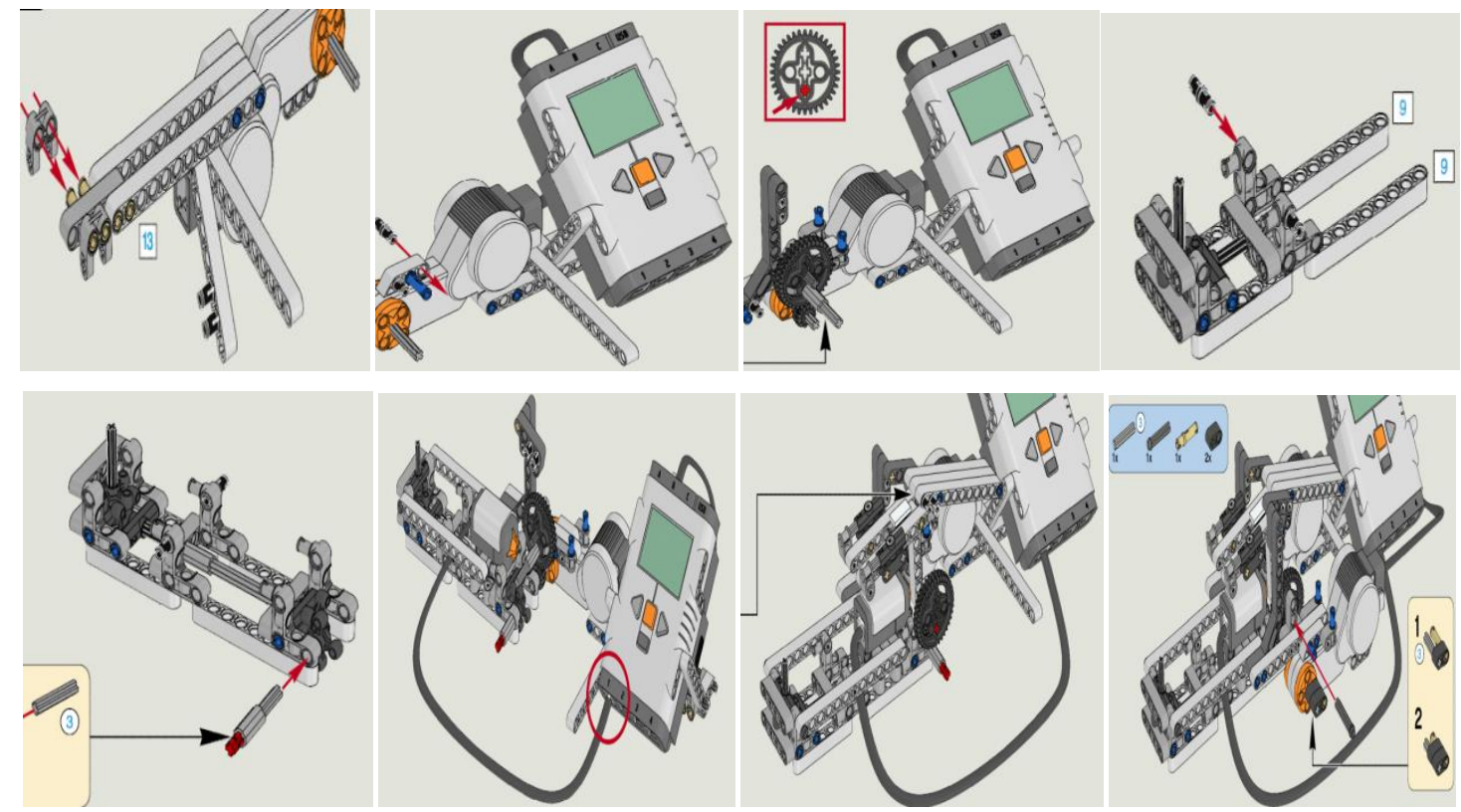

Fonte: http://www.lego.com/en-us/mindstorms/?domainredir=mindstorms.lego.com 
e-Mosaicos - Revista Multidisciplinar de Ensino, Pesquisa, Extensão e Cultura do Instituto de Aplicação Fernando Rodrigues da Silveira (CAp-UERJ) V. 6 - N. 12 - AGOSTO 2017 - ISSN: 2316-9303

A segunda sequência consistiu da montagem do detector de cores formado por seis etapas.

Fig. 9: Robô separador de bolinhas

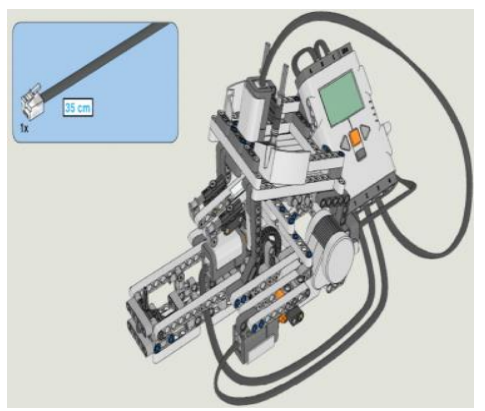

Fonte: http://www.lego.com/en-us/mindstorms/?domainredir=mindstorms.lego.com

Fig. 10: Robô separador de bolinhas - Cesto separador

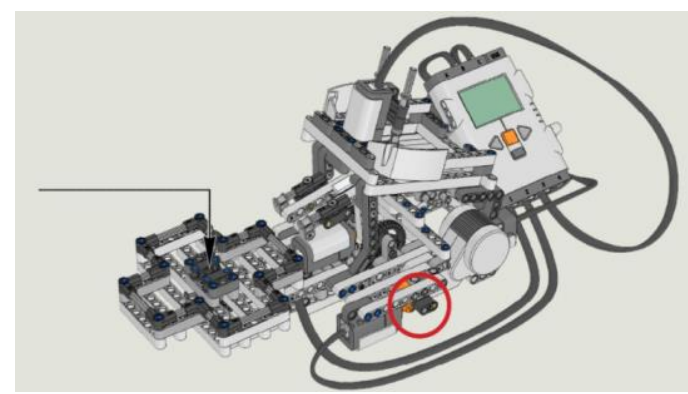

Fonte: http://www.lego.com/en-us/mindstorms/?domainredir=mindstorms.lego.com

A quarta sequência consistiu da montagem da catapulta de cores, constituída por vinte e duas imagens. Duas delas estão apresentadas nas figuras 11a e 11b.

Figs. 11a e 11b - Imagens extraídas da sequência da montagem da catapulta de cores do separador de bolinhas

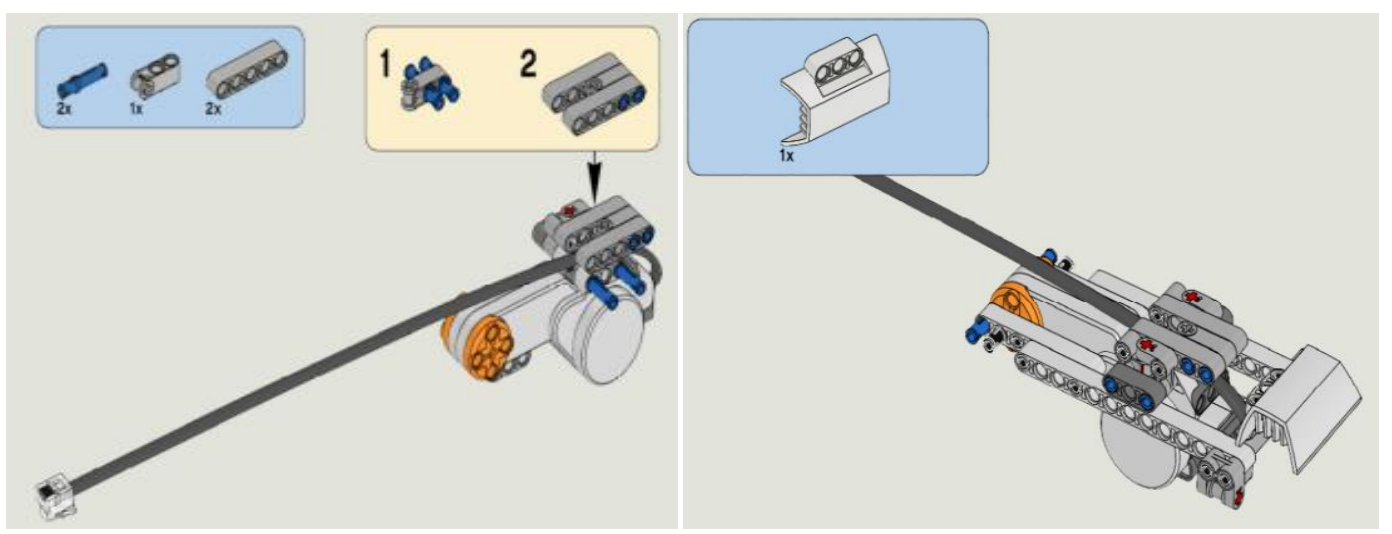

Fonte: http://www.lego.com/en-us/mindstorms/?domainredir=mindstorms.lego.com 


\section{A PROGRAMAÇÃo DO RoBÔ}

Até o momento forma exibidas algumas etapas das montagens realizadas pelos estudantes. Nesta sessão será tratada a programação do robô.

O kit de peças vem acompanhado de um CD-room que contém o software de programação. A programação utiliza imagens em todas as suas etapas, desde os blocos de programação até o menu de configurações dos blocos. A instalação do software fornece a primeira tela, onde a programação é iniciada.

Fig. 12: Ambiente de programação

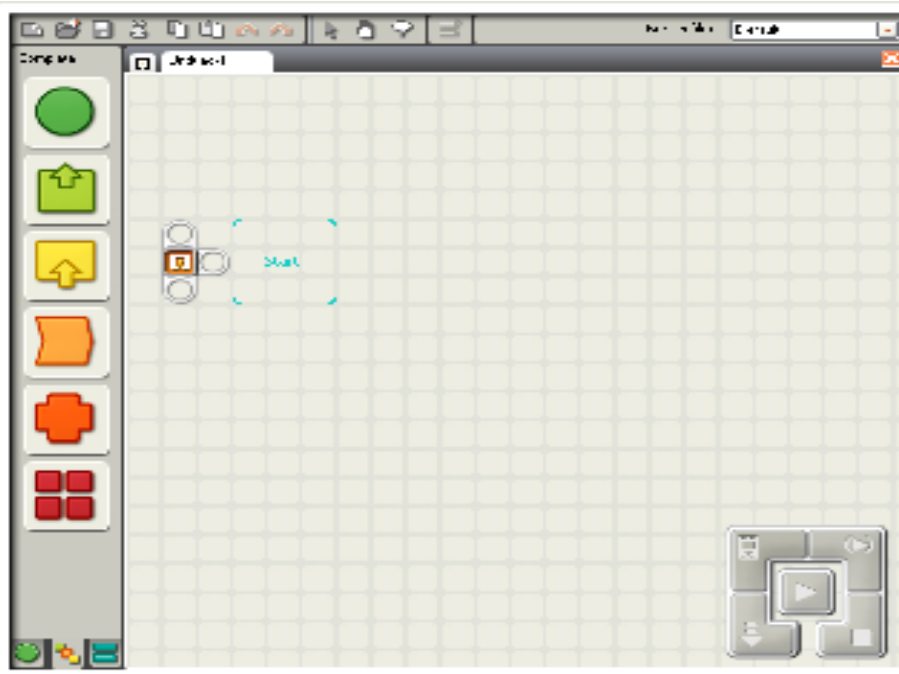

Fonte: material de pesquisa

A série de blocos do lado esquerdo constitui a Paleta de Comandos do software; em cada bloco da Paleta de Comandos está inserido outro conjunto de blocos que serão utilizados em cada programa. O grupo utilizou, principalmente, os seguintes blocos Paleta de Comandos: o "Common", o "Action" e o "Flow" que estão, respectivamente, mostrados a seguir:

"Action" - Nele está inserido o bloco motor, usado para controlar com precisão um servomotor de cada vez.

"Common"- Nele estão os blocos mais usados no projeto; os blocos move, que acionam os servomotores simultaneamente estão inseridos aqui. 
"Flow'- Nele estão inseridos os blocos de Estrutura de Controle, que servem para que o robô execute tarefas de acordo com as condições impostas pelo programador; os blocos de espera; de aguarde e de loop fazem parte deste conjunto.

Alguns dos blocos de programação bastante utilizados no projeto foram 0 move, o motor, o display, o loop, o sensor de luz/cor, o sensor de toque, o sensor de ultrassom e $o$ switch. Cada bloco do programa possui configurações que permitem variações que possibilitam ao robô executar as funções desejadas. A seguir estão alguns blocos e suas configurações:

Fig. 13 - Bloco Move - ambiente de programação: movimento para frente

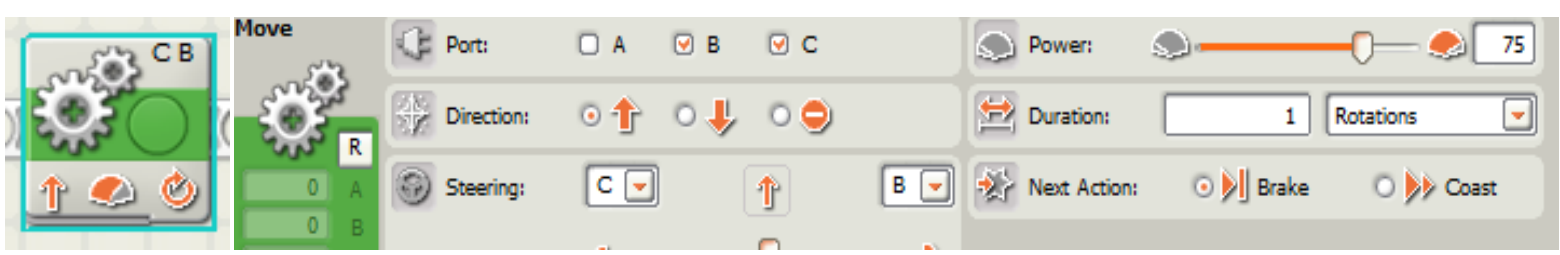

Fonte: material da pesquisa

O Bloco Move é configurado para controlar as portas B e C do servomotor; o movimento é para frente com uma potência de $75 \%$ do total; a duração do movimento está configurada em rotações; a próxima ação é parar.

Fig. 14 - Bloco Motor - ambiente de programação: movimentos curvilíneos

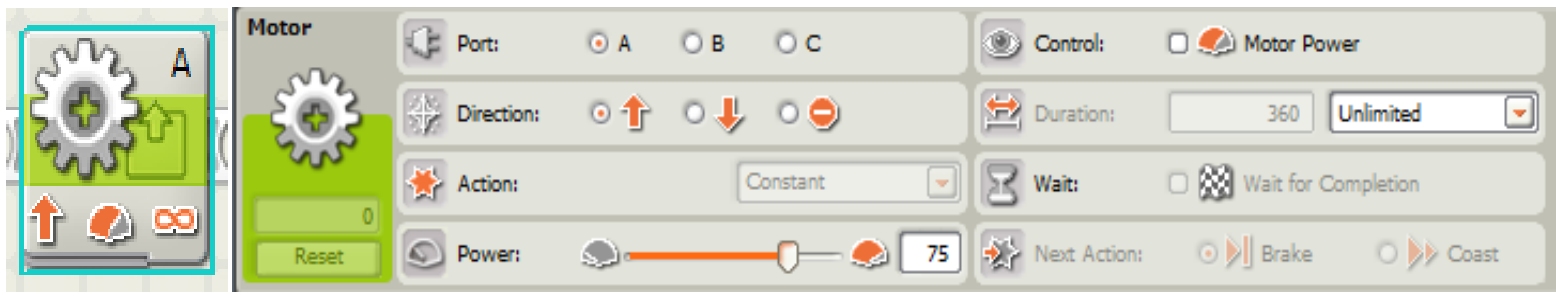

Fonte: material da pesquisa

O Bloco Motor é configurado para controlar a porta A do servomotor; o movimento é para frente com uma potência de $75 \%$ do total; este bloco permite que os motores funcionem de forma independente, ou seja, as potências dos 
servomotores podem ser diferentes; no caso de o robô descrever trajetórias curvilíneas, este é fundamental.

Fig. 15 - Ambiente de programação - comunicação de conclusão da tarefa

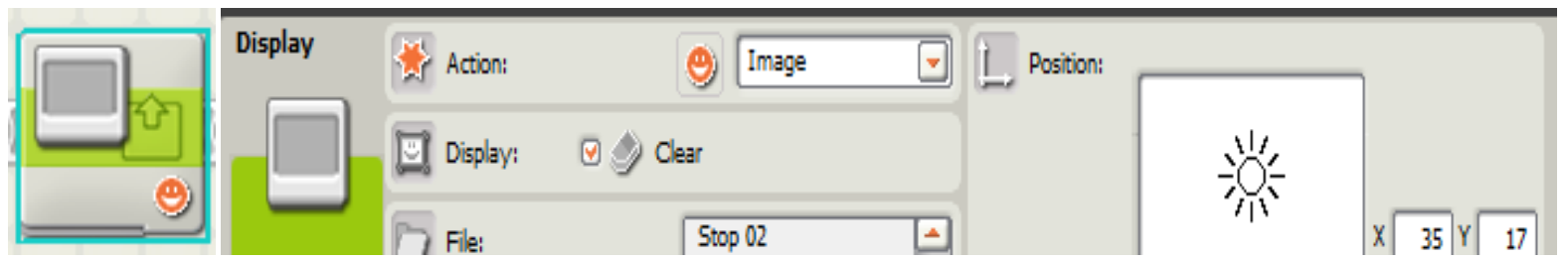

Fonte: material da pesquisa

O Bloco Display é configurado para mostrar a imagem de um Sol, que representa o cérebro do robô quando terminar de executar determinada tarefa.

Fig. 16 - Ambiente de programação - loop

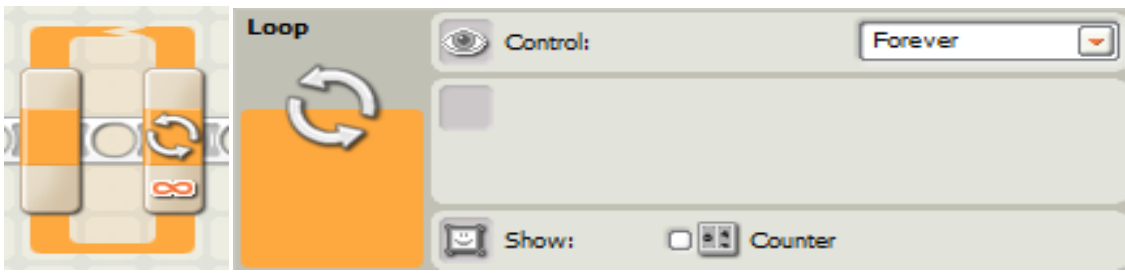

Fonte: material da pesquisa

Fig. 17 - Ambiente de programação - reconhecimento de cor

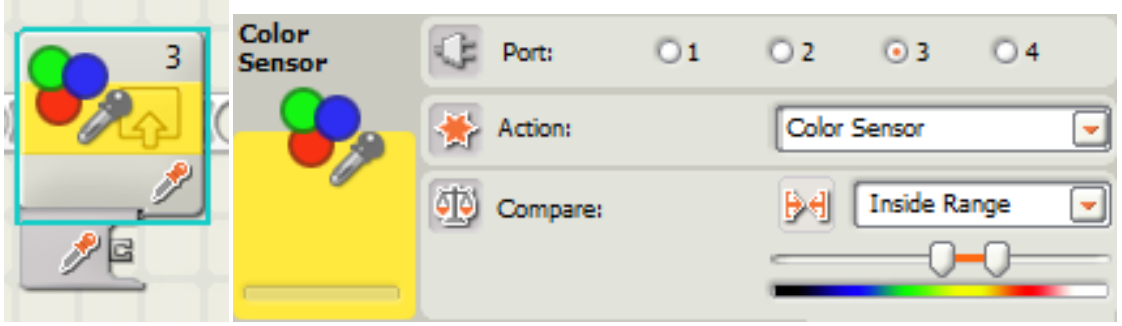

Fonte: material da pesquisa

O Bloco Sensor de Cor, que pode ser utilizado no modo luz, ligado à porta 3 do cérebro do robô, é configurado para trabalhar, por comparação, na faixa de comprimentos de onda do amarelo. 
Fig. 18 - Ambiente de programação - sensibilidade ao toque

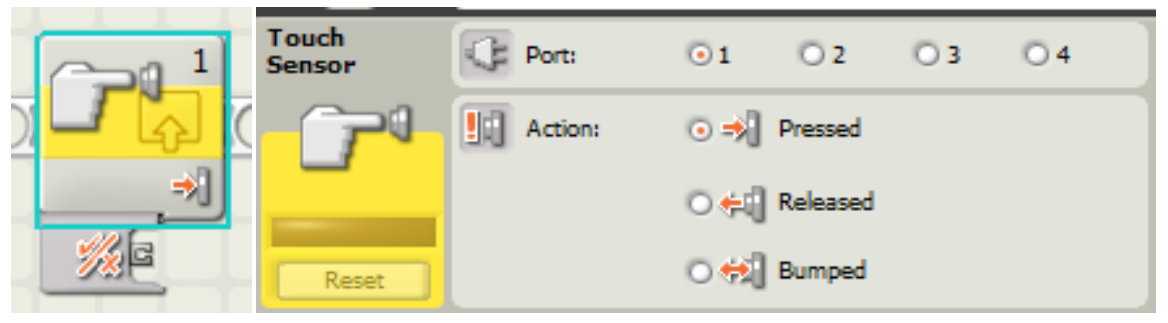

Fonte: material de pesquisa

O Bloco Sensor de Toque é ligado à porta 1 do cérebro do robô. Este funciona pressionado, liberado ou quando apenas colide. Na programação é inserido e, caso uma destas condições se verifique, o robô executará determinada ação.

Fig. 19 - Ambiente de programação - visão ultrassom

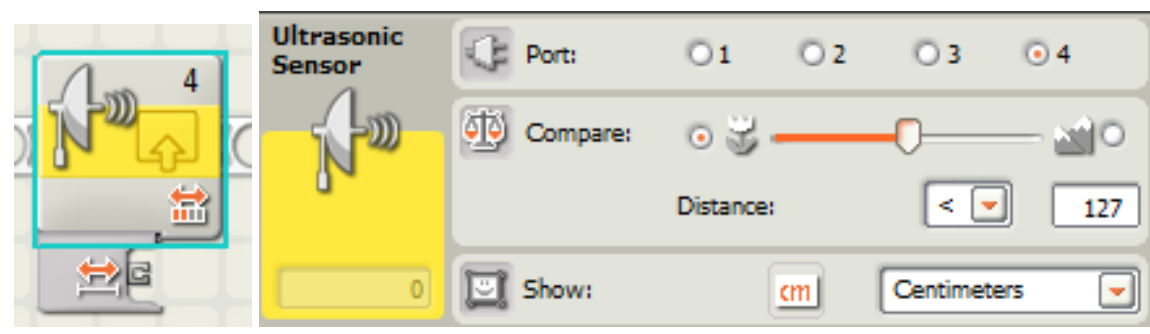

Fonte: material de pesquisa

O Bloco Sensor de Ultrassom é ligado à porta 4 do cérebro do robô. Este envia ondas ultrassônicas que atingem os objetos à sua frente e são refletidas de volta ao sensor. Pelo tempo de viagem da onda, a distância até o objeto é calculada. No caso, para objetos a uma distância menor do que 127 centímetros, alguma ação será realizada pelo robô.

Fig. 20 - Ambiente de programação - sensor de luz

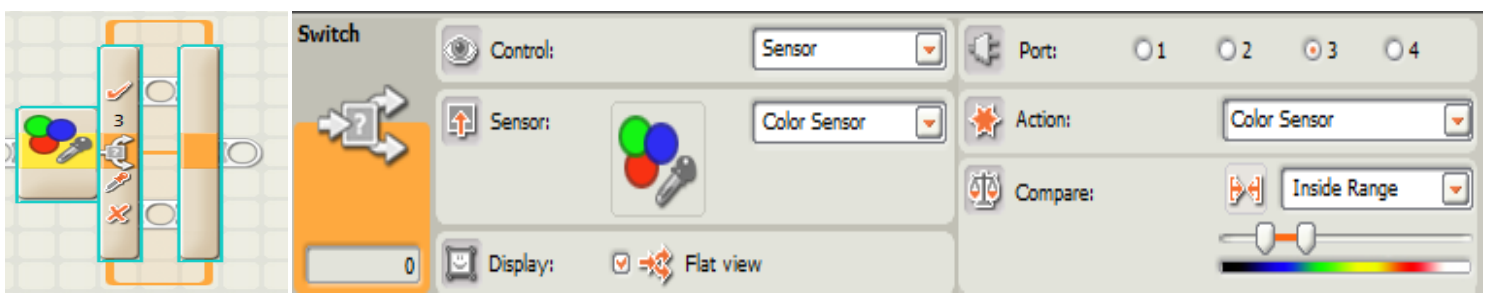

Fonte: material de pesquisa 
O Bloco Switch, acoplado ao sensor de luminosidade no modo sensor de cor, é um dos blocos mais fundamentais da programação, pois tem a função de decisão. Na configuração acima teremos uma série de ações executadas quando for detectada a cor azul e, outra série de ações quando esta cor não for detectada. Um exemplo seria, caso o robô detectasse um objeto de cor azul, ele seguiria em frente, caso não detectasse esta cor, ele poderia girar em $90^{\circ}$ para a direita.

A esta altura deve estar claro a importância da imagem na compreensão da lógica dos algoritmos a serem desenvolvidos e na montagem das estruturas dos robôs. Esclarecemos, finalmente, que os programas são transferidos para o cérebro do robô através de um cabo USB.

\section{O Robô seguidor de Trajetórias}

Dentro da área de Engenharia, sobretudo na parte de controle e automação, existe um problema clássico, denominado "O seguimento de trajetórias". Este consiste na realização autônoma de trajetórias por um sistema ou máquina e estão presentes em voo de aeronaves, na navegação de submarinos não tripulados e no controle de mãos robóticas em operações de inspeção e manipulação dentro do corpo humano.

Tendo em mente o objetivo de investigar mais de perto o problema do seguimento de trajetórias, os estudantes envolvidos no projeto de robótica educativa realizaram a montagem e a programação deste robô e propuseram extensões ou variações deste problema básico. Os conceitos da área de Física Básica foram bastante explorados durante a realização do estudo, contando com textos visuais em cada etapa da realização.

O robô seguidor de trajetória foi montado e programado para andar sobre uma linha preta pintada em um fundo branco. Para tal, foi introduzido na parte da frente do robô um sensor de luz, configurado para operar no modo cor. Assim o sensor de luz emite luz de comprimentos de onda nas faixas do vermelho, azul e verde e, quando incide sobre a superfície negra nenhuma luz é refletida de volta ao sensor. Ao atingir a superfície branca, toda a luz incidente é refletida de volta ao sensor. As imagens da figura 21 mostram o robô seguidor de trajetórias e a trajetória, em seu modelo padrão: 
Figs. 21a e 21b: Design do Robô e Circuito proposto pelo fabricante
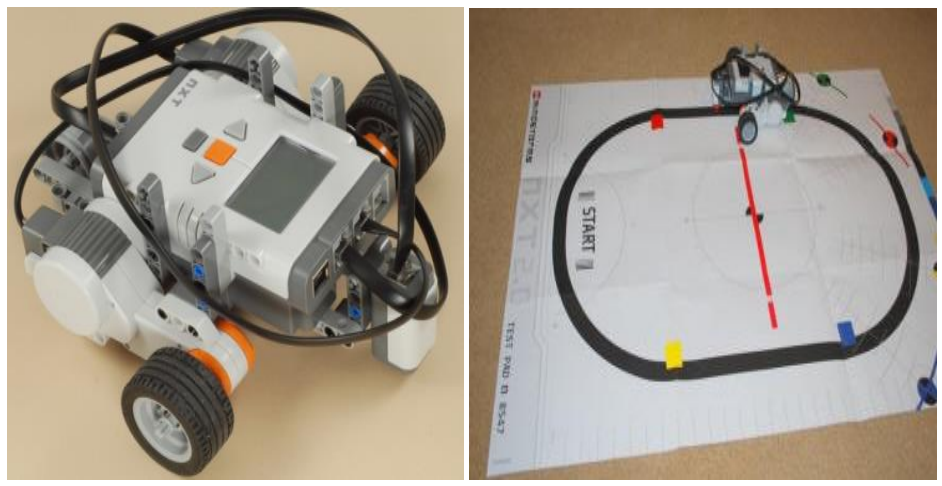

Fonte: Material da Pesquisa

O texto da programação é composto de uma sequência de cerca de quarenta imagens, conforme a tela de programação e as configurações utilizadas para cada bloco na implementação do algoritmo:

Fig. 22 - Programação de ação - seguir trajetória - tela de programação

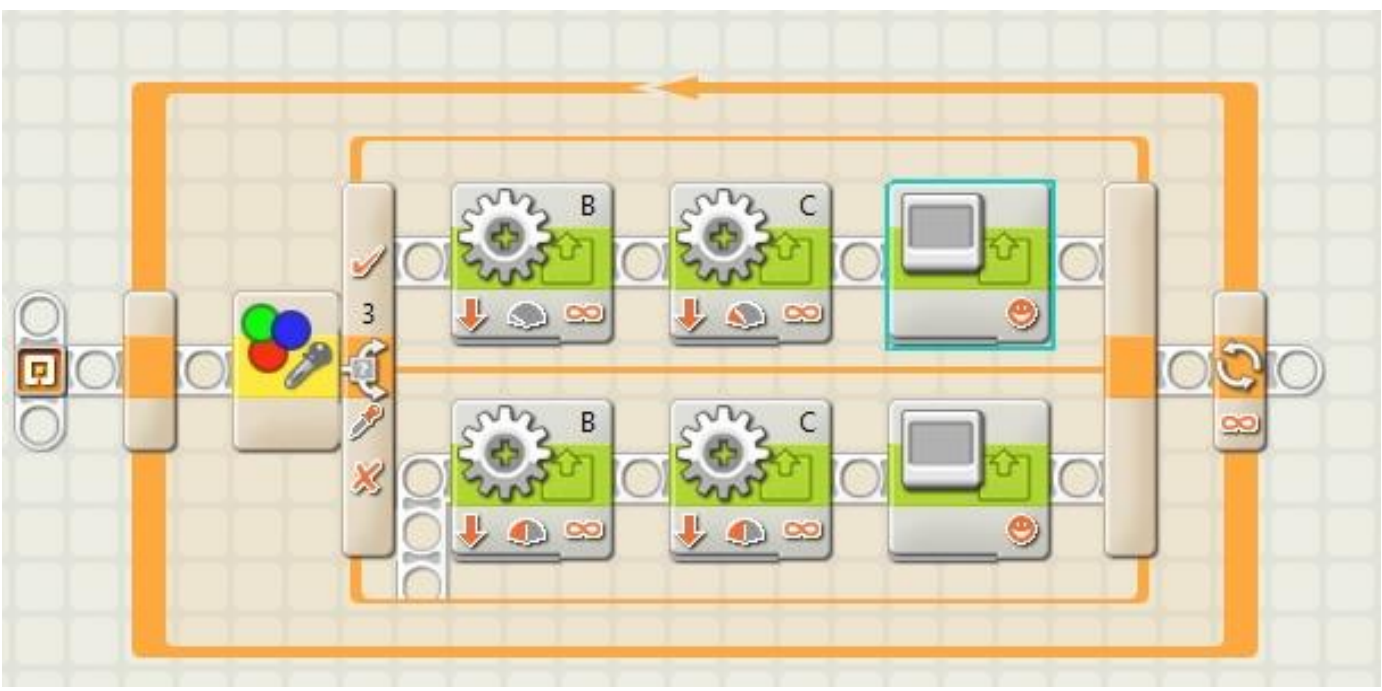

Fonte: Material da Pesquisa 
Fig. 23 - Programação de ação - seguir trajetória - movimento

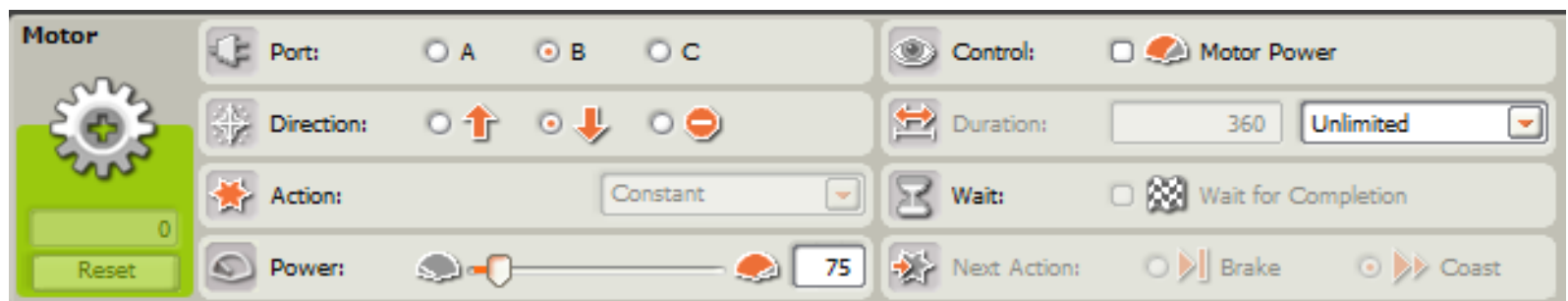

Fonte: material da pesquisa

Dentro de um LOOP de repetição infinita estão inseridos quatro blocos "motor", atuando sobre os dois servomotores, dois blocos de "display" e um bloco do sensor de luz, programado para atuar como sensor de cor. Há também um bloco "switch", ou "IF". O programa acima nos diz o seguinte:

Se o sensor de cores consegue detectar a pista, de cor preta, os blocos "motor" fazem com que o robô se mova para frente e para fora da pista. Nesta situação, o robô vai para uma cor não selecionada. O bloco do "display" faz surgir uma imagem confirmando que a ação foi feita. Ao detectar uma cor não selecionada, o bloco motor faz o robô se mover para dentro da pista e o bloco do "display" faz surgir mais uma vez uma imagem mostrando a confirmação do movimento.

Desta forma o robô movimenta-se sobre a linha de fronteira, entre o branco e o preto, em um verdadeiro zigue-zague.

Um dos maiores desafios desta empreitada foi buscar um movimento preciso do robô sobre as linhas pretas. Dependendo das trajetórias propostas, as curvas eram mais ou menos acentuadas, e as potências dos servomotores deveriam ser ajustadas, pois o robô não tem um diferencial, como a maioria dos carros, para distribuir o movimento vindo do motor para as rodas. A seguir têm-se imagens de algumas das trajetórias estudadas:

Fig. 24 - Trajetórias pesquisadas
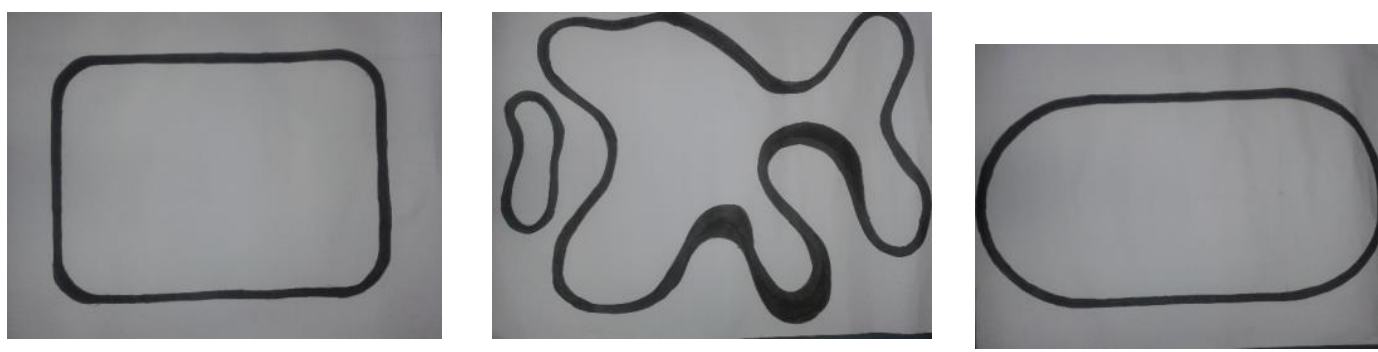

Fonte: material de pesquisa 
Imagens das trajetórias, ou dos caminhos, criados pelos estudantes para avaliar o desempenho do robô. Para cada caminho proposto foi realizado um estudo sobre a relação entre as potências do bloco motor de cada servomotor. Para cada curva, de cada trajetória, foi obtida uma configuração diferente.

\section{Conclusões dos estudos de programação}

Em linhas gerais, após toda a investigação, o grupo concluiu que o movimento só é executável em qualquer tipo de trajetória ao exercer sobre as mesmas pequeníssimas rotações alternadas sobre a programação de um sensor de cor instruídos por blocos de motor todos inseridos em um loop. Para isto é necessário que haja alternância na potência dos motores no "IF" sim e no "IF" não e mantenha a diferença nas potências de cada porta do motor dentro de uma condicionante, "se".

RESULTADOS DA APRENDIZAGEM PROPORCIONADA PELA REALIZAÇÃO DO PROJETO DE ROBÓTICA EDUCATIVA

Alguns dos resultados decorrentes deste projeto de Robótica Educativa são apresentados a seguir em duas vertentes: na proposição dos estudantes, que são extensões do robô seguidor de trajetórias pensadas por eles, e nos conceitos de Física Básica estudados durante a realização das empreitadas.

\section{Proposição dos estudantes, decorrentes da pesquisa $^{8}$}

Os estudantes envolvidos imaginaram a possibilidade de um robô que pudesse ser utilizado na superfície de um planeta, controlado para seguir determinada trajetória, e que nele fosse acoplado um braço que seria acionado toda vez que algum obstáculo fosse detectado. Utilizando a montagem básica do robô seguidor de trajetórias foi acoplado ao robô um sensor de ultrassom e um braço mecânico. Cada vez que o robô seguidor de trajetórias com sensor de ultrassom acoplado detectasse, ao enviar uma onda ultrassônica, por reflexão, ou eco, um objeto a uma distância menor ou igual a sete centímetros, o braço mecânico seria acionado e o objeto seria afastado do caminho.

A figura 25 mostra o "robô seguidor de linhas, rebatedor de objetos, com sensor de ultrassom", proposto pelos estudantes da Educação Básica:

\footnotetext{
${ }^{8}$ Os modelos produzidos estão publicados em vídeo em canal youtube. As URLs estão listadas nas referências.
} 
Fig. 25: Robô seguidor de trajetória com braço mecânico

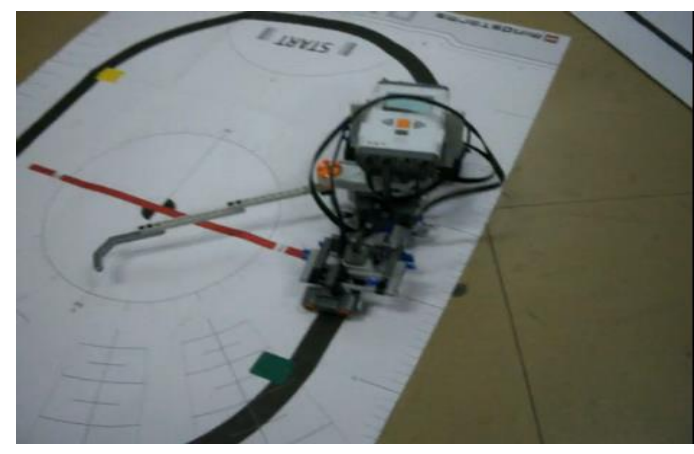

Fonte: material de pesquisa

O algoritmo da programação para este dispositivo está na figura 26:

Fig. 26: Algoritmo de programação do robô seguidor de trajetória com braço mecânico

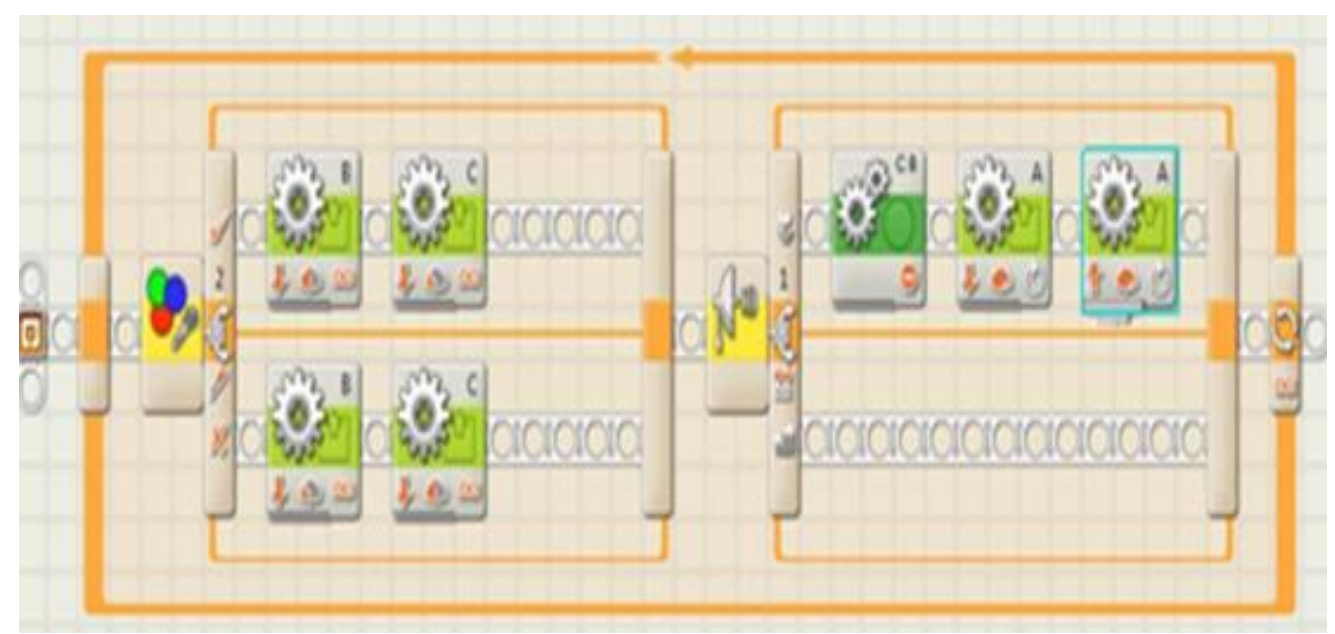

Fonte: material de pesquisa

\section{Conceitos de Física estudados durante a realização das etapas da pesquisa}

Para cada empreitada realizada durante o desenvolvimento do projeto, conceitos de Física foram estudados. Tomando sempre como base o robô seguidor de linhas, que "enxerga" a linha através da emissão e posterior reflexão de luz, conforme já foi elucidado ao longo do texto, tivemos os seguintes subprojetos: 1) o robô seguidor de linhas percorrendo circuitos diferentes, com curvas mais fechadas e mais abertas: neste caso, os conceitos estudados foram a cinemática do movimento curvilíneo, o movimento das rodas do robô para fazer as curvas mais e menos acentuadas, o estudo de engrenagens, o conceito de torque, o estudo do diferencial, presente nos automóveis, e o conceito de potência; 2) o robô seguidor de linhas com variações no Design, de modo que sua estrutura ficasse mais horizontal ou mais 


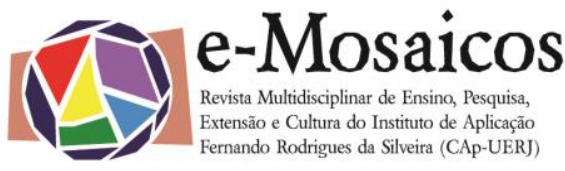

DOI 10.12957/e-mosaicos.2017.28610

vertical. Isto fez com que houvesse uma variação no centro de gravidade do robô, e este conceito foi explorado. Nesta empreitada foi acoplado à parte frontal do robô o sensor de toque, que funciona como um interruptor de luz. Este era ligado ou desligado sempre que encostava em um obstáculo. Este sensor serviu de base para a realização do estudo dos circuitos elétricos simples; 3) no caso do robô rebatedor de objetos, forma estudadas ondas sonoras, já que este possuía um sensor de ultrassom, programado para acionar um braço sempre que detectasse um objeto a uma distância igual a sete centímetros. A partir do movimento do braço foram construídos o conceito de Conservação da Quantidade de Movimento e de Lançamento Oblíquo.

\section{CONSIDERAÇõES FINAIS}

As reformas curriculares oriundas na Lei de Diretrizes e Bases da Educação Brasileira estabelecem que o estudante, ao concluir a Educação Básica, está encerrando uma etapa de sua formação e, portanto, ao deixar a escola deve ser um cidadão crítico, capaz de avaliar os avanços tecnológicos produzidos pela sociedade nas últimas décadas. Sob este aspecto a introdução da Robótica Educativa no Ensino Médio revela-se como uma ferramenta extremamente rica e poderosa na área de Educação, notadamente na dimensão tecnológica.

A motivação original do projeto de robótica, que alguns dos resultados acabamos de apresentar, era estimular o interesse dos alunos da Educação Básica nos cursos de Engenharia e proporcionar aos participantes do projeto, estudantes daquele nível de escolaridade, um primeiro contato com esta profissão. Para isso foi utilizado um kit de robótica educacional que permitiu a abordagem de conceitos teóricos e práticos não apenas associados às disciplinas do ensino médio tais como Matemática e Física, mas também alguns conceitos pouco abordados pelas mesmas, tais como trabalho em equipe, autodesenvolvimento, capacidade de solucionar problemas, senso crítico, interdisciplinaridade, exposição de pensamentos, criatividade e autonomia. Ao final do projeto, acabamos por explorar bastantes conceitos de Física. O projeto foi financiado pelo CNPq e teve duração de um ano, já tendo sido concluído. Dos quatro alunos da Educação Básica participantes, três deles estão cursando Engenharia, um fazendo Engenharia de Controle e Automação, outro fazendo Engenharia Eletrônica e de Computação e o terceiro, cursando Engenharia Elétrica.

Neste artigo, especificamente, enfatizamos a iniciação à Robótica, através da abordagem interdisciplinar entre a Física e a Linguagem Visual, que no Ensino Médio corresponde a uma abordagem do Desenho como Tecnologia Gráfica, através da utilização de imagens. Um aspecto relevante a considerar é o fato de que diferentes tipos de textos atendem às necessidades do estudo. 0 manual é descritivo orienta a montagem pela simples sequenciação das imagens das etapas. E, embora pareça óbvio, a subversão desse princípio pode inviabilizar alguma etapa da montagem. Além disso, essa noção adquire maior importância, ainda, na elaboração de manuais 
de montagem das propostas desenvolvidas pelo grupo, tanto para outros usuários quanto para registro para o relatório da pesquisa.

A tela da programação e as janelas do menu constituem textos argumentativos para discussões em aulas regulares de Física, junto com análises de simulações. Ou ainda, para a proposição de problemas. A esse propósito, esses estudos podem focalizar também a produção de sequências didáticas para as séries iniciais do ensino fundamental. Tais materiais podem conter narrativas, simulações e propostas/desafios de montagem de modelos adequados à faixa. Nelas as cores poderiam ter significados para além, do código da programação: memórias sensoriais e sociais, que contribuíssem para reflexões culturais, éticas, estéticas.

Por fim, não se ignorar possíveis obstáculos à aprendizagem decorrentes das diferenças individuais, ou seja, a existência de menor ou maior afinidade do estudante com determinado sistemas de signos. Alguns alunos possuem maior ou menor habilidade de leitura e produção de textos visuais, verbais ou musicais. Assim, o estudo da recepção dos mesmos em diferentes grupos de alunos contribui para potencializar a aprendizagem através de ações que contemplem tais diferenças. De modo que estimule a ampliação da habilidade de leitura e expressão em diferentes sistemas bem com a aprendizagem de uma disciplina, nesse caso, a Física, em particular.

\section{REFERÊNCIAS BIBLIOGRÁFICAS}

BAKHTIN, M. Marxismo e filosofia da linguagem. São Paulo: Hucitec, 1997 . Estética da criação verbal. São Paulo: Martins Fontes, 1992

BARTHES, Roland. A Retórica da Imagem. In: O óbvio e o obtuso. Rio de Janeiro: Martins Fontes,1990.

CALABRESE, O, org. Semiotica della pintura. Milano: IISaggiatore, 1980

ECO, H. Tratado Geral de Semiótica. São Paulo: Perspectiva, 2003

EDGERTON, S. The Renaissance Rediscovery of Linear Perspective. New York, Basic Books, 1975

FARINA, M. Psicodinâmica das cores em Comunicação. São Paulo: Editora Blucher, 1986.

KRESS, G. R. e van LEEUWEN, T. Multimodal Discourse: the modes and media of contemporary communication. London: Arnold, 2001.

MANGUEL, A. Lendo imagens. uma história de amor e ódio. São Paulo: Companhia das Letras, 2001. 
MACHADO, A. O Quarto Iconoclasmo: O Quarto Iconoclasmo e outros ensaios hereges. Rio de Janeiro: Rios Ambiciosos, 2001.

MARCUSCHI, Luiz Antonio. Gêneros textuais: definição e funcionalidade. In: DIONÍSIO, A.P.; MACHADO, A.R.; BEZERRA, M.A. Gêneros textuais e ensino. Rio de Janeiro: Lucerna, 2002. Pp. 19-36.

SANTAELLA, L; NOTH, W. Imagem: cognição, semiótica e mídia. São Paulo: Iluminuras, 2008.

SECCHI, H.A. Una Introducción a los Robots Móvilles, Instituto de Automática INAUT, Universidade Nacional de San Juan - UNSJ, Argentina. 2008.

THUILLIER. P. De Arquimedes a Einstein: a face oculta da invenção científica. Rio de Janeiro: Jorge Zahar, 1994.

\section{Vídeos Produzidos:}

1. Vídeo com montagem e circuito do fabricante: http://www.youtube.com/watch?v=zrWuqS3uN8k

2. Vídeo com montagem do fabricante e circuito proposto pelo grupo: http://www.youtube.com/watch?v=X7ZuUfib9Vg

3. Vídeo 1 do seguidor de linhas com ultrassom e rebatedor de objetos: http://www.youtube.com/watch?v=EUS4Y7fmEMY

4. Vídeo 2 do seguidor de linhas com ultrassom e rebatedor de objetos: http://www.youtube.com/watch?v=zsPk3faFjDY

5. Vídeo 3 do seguidor de linhas com ultrassom e rebatedor de objetos: http://www.youtube.com/watch?v=fltWVC zc8I

6. Vídeo 4 do seguidor de linhas de pé para estudo do equilíbrio: http://www.youtube.com/watch?v=XRb-yvQUj80

7. Vídeo 5 do seguidor de linhas de pé para estudo do equilíbrio: http://www.youtube.com/watch?v=G4hFcux8jkM 